\title{
Disparities in the survival of endometrial cancer patients in a public healthcare system: A population-based cohort study.
}

\author{
Limor Helpman ${ }^{1}$, Gregory Pond ${ }^{1}$, Laurie Elit ${ }^{1}$, Laura Anderson ${ }^{2}$, Iwa Kong ${ }^{1}$, Kara \\ Schnarr $^{1}$, and Hsien Seow ${ }^{1}$ \\ ${ }^{1}$ Juravinski Cancer Centre \\ ${ }^{2}$ McMaster University Faculty of Health Sciences
}

December 1, 2020

\begin{abstract}
Objective: Social determinants of health $(\mathrm{SDH})$ have been shown to correlate with adverse cancer outcomes. It is unclear if their impact goes beyond behavioral risk or healthcare access. We aimed to evaluate the association of SDH with endometrial cancer outcomes in a public healthcare system. Design and Setting: A retrospective cohort study of endometrial cancer patients in Ontario, Canada. Population: Women diagnosed with endometrial cancer in Ontario between 2009-2017. Methods: Clinical and sociodemographic variables were extracted from administrative databases. Validated marginalization scores for material deprivation, residential instability and ethnic concentration were used. Associations between marginalization and survival were evaluated using log-rank testing and Cox proportional hazards regression. Results: 20228 women with endometrial cancer were identified. Fewer patients in marginalized communities presented with early disease $(70 \%$ vs. $76 \%, \mathrm{p}<0.001)$ and received surgery $(89 \%$ vs. $93 \%, \mathrm{p}<0.001)$. Overall survival was shorter among marginalized patients $(\mathrm{p}<0.001)$. On multivariable analysis adjusted for patient and disease factors, overall marginalization ( $\mathrm{HR}=1.22,95 \%$ CI 1.03-1.08), material deprivation $(\mathrm{HR}=1.22,95 \% \mathrm{CI} 1.10-1.35)$ and residential instability $(\mathrm{HR}=1.32,95 \%$ CI 1.19-1.46) were associated with increased risk of death $(\mathrm{p}<0.001)$. Conclusions: Socioeconomic marginalization is associated with an increased risk of death in endometrial cancer patients. Targetable events in the cancer care pathway should be identified to improve health equity Funding: This study was supported by a grant (\#RD-196) from the Hamilton Health Sciences Juravinski Hospital and Cancer Center Foundation Keywords: uterine cancer, endometrial cancer, social determinants of health
\end{abstract}

Disparities in the survival of endometrial cancer patients in a public healthcare system: A population-based cohort study.

running title: social marginalization compromises uterine cancer survival

Limor Helpman, MD ${ }^{\mathrm{a}, \mathrm{d}}$, Gregory R. Pond, $\mathrm{PhD}^{\mathrm{b}, \mathrm{c}, \mathrm{d}}$, Laurie Elit, MD ${ }^{\mathrm{a}, \mathrm{b}, \mathrm{c}}$, Laura N. Anderson, $\mathrm{PhD}^{\mathrm{d}}$, Iwa Kong, $\mathrm{MD}^{\mathrm{c}}$, Kara Schnarr, $\mathrm{MD}^{\mathrm{c}}$, Hsien Seow, $\mathrm{PhD}^{\mathrm{c}, \mathrm{d}}$

${ }^{a}$ Division of Gynecologic Oncology, Juravinski Cancer Centre

Department of Obstetrics \& Gynecology, McMaster University

Hamilton, ON, Canada

b Escarpment Cancer Research Institute

McMaster University

Hamilton, ON, Canada

${ }^{c}$ Department of Oncology, Juravinski Cancer Centre 
McMaster University

Hamilton, ON, Canada

d Department of Health Research Methods, Evidence and Impact

McMaster University

Hamilton, ON, Canada

\section{Corresponding author: Limor Helpman, MD, MPH}

Division of Gynecologic Oncology Department of Obstetrics \& Gynecology, McMaster University Juravinski Cancer Centre 699 Concession St. Hamilton, ON, L8V5C2, Canada lhelpman@gmail.com tel \#905-3879495 fax \#905-5756343

\section{ABSTRACT (word count: 237)}

Objective: Social determinants of health (SDH) have been shown to correlate with adverse cancer outcomes. It is unclear if their impact goes beyond behavioral risk or healthcare access. We aimed to evaluate the association of SDH with endometrial cancer outcomes in a public healthcare system.

Design and Setting: A retrospective cohort study of endometrial cancer patients in Ontario, Canada.

Population: Women diagnosed with endometrial cancer in Ontario between 2009-2017.

Methods: Clinical and sociodemographic variables were extracted from administrative databases. Validated marginalization scores for material deprivation, residential instability and ethnic concentration were used. Associations between marginalization and survival were evaluated using log-rank testing and Cox proportional hazards regression.

Results: 20228 women with endometrial cancer were identified. Fewer patients in marginalized communities presented with early disease $(70 \%$ vs. $76 \%, \mathrm{p}<0.001)$ and received surgery $(89 \%$ vs. $93 \%, \mathrm{p}<0.001)$. Overall survival was shorter among marginalized patients $(\mathrm{p}<0.001)$. On multivariable analysis adjusted for patient and disease factors, overall marginalization $(\mathrm{HR}=1.22,95 \%$ CI 1.03-1.08), material deprivation ( $\mathrm{HR}=1.22$, $95 \%$ CI 1.10-1.35) and residential instability $(\mathrm{HR}=1.32,95 \%$ CI 1.19-1.46) were associated with increased risk of death $(\mathrm{p}<0.001)$.

Conclusions: Socioeconomic marginalization is associated with an increased risk of death in endometrial cancer patients. Targetable events in the cancer care pathway should be identified to improve health equity

Funding: This study was supported by a grant (\#RD-196) from the Hamilton Health Sciences Juravinski Hospital and Cancer Center Foundation

Keywords: uterine cancer, endometrial cancer, social determinants of health

Tweetable abstract: Even in a public healthcare system with few barriers to care, socioeconomic marginalization is linked with an increased risk of death among endometrial cancer patients.

\section{INTRODUCTION}

The World Health Organization and National Cancer Institute have identified Social Determinants of Health (SDH) as a broad constellation of social, cultural and financial conditions that have a profound influence on the trajectory of health and healthcare ${ }^{1-3}$. Significantly, SDH are recognized as impactful forces across the cancer care pathway ${ }^{4-6}$. Health disparities have been identified both at the global and individual levels, with an inequitable distribution of disease burden and disparate outcomes ${ }^{7-10}$. The international community has recognized that these disparities need to be prioritized in national and international cancer control programs $4,9,11$.

Endometrial cancer is the most common gynecologic cancer in women in North America ${ }^{12}$, and ranks sixth most common among all cancers in women worldwide ${ }^{9}$. Unlike many cancers extensively studied in health 
equity research, endometrial cancer has few behavioral risk factors and no screening program; increased risk and poor compliance with screening are therefore unlikely to play a role in any associations of disease outcomes with social or cultural marginalization. In spite of this, correlations between sociodemographic factors and endometrial cancer presentation ${ }^{13-17}$, management ${ }^{18-23}$ and prognosis ${ }^{13,18,24,25}$ have been shown in some studies.

The majority of publications evaluating the associations between social determinants of health (SDH) and endometrial cancer outcomes originate in the United States ${ }^{13,18,20,24-27}$, where socioeconomic factors often directly drive access to, and quality of care. In Canada, Ontario's population is in many ways comparable to the US population ${ }^{28}$, but its healthcare system is publicly funded and offers universal access. Despite reduced socioeconomic barriers to healthcare, disparities have been demonstrated for some cancers in Ontario 8,29,30; however, no evaluation of SDH and endometrial cancer outcomes in Canada has been published to date.

Understanding the associations between SDH and endometrial cancer outcomes in a universal access healthcare system could elucidate the mechanisms of impact of these patient factors on disease trajectory, and present opportunities for improved patient and provider education and advocacy, distribution of resources and the promotion of health equity. The primary objective of this study was to evaluate the association between social determinants of health and survival among endometrial cancer patients in Ontario, Canada.

\section{METHODS}

A population-based retrospective cohort study of endometrial cancer patients was conducted in the province of Ontario, Canada. Women with endometrial cancer diagnosed 2009-2017 were identified from the Ontario Cancer Registry, which uses a rapid case ascertainment system to capture all cancer diagnoses in the province based on pathology reports as well as admission and discharge databases, regional cancer treatment reports and death certificates ${ }^{31}$, and has undergone rigorous quality analysis as part of a global cancer surveillance project $^{32}$. All uterine endometrial cancer histologies were included, but uterine sarcomas were excluded. Populations excluded from Ontario's provincial administrative healthcare databases, including incarcerated persons, Canadian armed forces and Indigenous people living on Reserves whose healthcare is federally funded, were not included in the study population. The timeframe chosen was selected to reflect a period in which stage information began to be systematically entered in the Ontario Cancer Registry, and was cut off to allow for latency in reporting.

The study, using de-identified secondary data analysis, was reviewed and exempted by the Hamilton Health Sciences integrated research ethics board (\#7732-C).

Data sources:

We obtained linked administrative data through IC/ES, formerly known as the Institute of Clinical and Evaluative Sciences of Ontario. Demographic data was available from the Ontario Registered Person Database. The modified Charlson-Deyo comorbidity score was calculated based on diagnoses registered for patients at hospital admissions in the year preceding surgery ${ }^{33}$. Severe obesity (class 3 obesity, BMI $>40$ according to the CDC classification) was collected from unique surgical and anesthesia billing codes. Procedures and treatments were extracted from the Ontario Health Insurance Plan databases, used for documenting and billing all healthcare interactions by providers, and from the Discharge Abstract Database maintained by the Canadian Institute of Health Information (CIHI). Cancer diagnoses and histologies, as well as stage information, is collected by Cancer Care Ontario (CCO) in the Ontario Cancer Registry. CCO collects stage data based on the staging criteria of the American Joint Committee on Cancer or the Collaborative Stage initiative. For cases with more than one valid stage value, a resolved "best stage" is derived based on a pre-specified algorithm. Overall survival, from diagnosis to death, was defined as the primary outcome for this analysis.

Exposure variables, including marginalization scores, income quintiles and rural vs. urban residency, are neighborhood-based and assessed using conversion software from Statistics Canada to match individuals' 
postal codes to small geographical units (Census Tracts and Dissemination Area) ${ }^{34}$. The Marginalization Score is an Ontario adaptation of the Canadian Marginalization Index previously validated for health research in Ontario and includes domains of material deprivation, residential instability, dependency and ethnic concentration ${ }^{35}$. The residential instability index reflects housing instability, number of residents per dwelling, family unit size and composition. The material deprivation index includes information on education, income, government support and unemployment. The ethnic concentration index reflects the proportion of new immigrants ( $<5$ years) in the community and those who self-identify as a minority. The dependency index reflects the proportion of seniors and dependent minors in the community; since uterine cancer is prevalent in women in their 60 s and 70 s and is uncommon in young women, the dependency scale was not considered relevant in this population and was therefore not used in this analysis. Each of the three domains in the index were evaluated separately and as a combined summary marginalization score, as previously reported ${ }^{35}$. Marginalization indices are reported in quintiles, where quintile 5 reflects the highest degree of marginalization.

\section{Statistical Analysis:}

Descriptive statistics were used to summarize patient, tumor and treatment characteristics as well as outcomes. A summary marginalization score combined scores from the three marginalization domains considered in this analysis (material deprivation, residential instability and ethnic concentration). Patients were stratified by marginalization quintiles and their characteristics were compared using the chi-square test for categorical and ordinal data or Wilcoxon rank sum test for continuous data.

The primary outcome was defined as overall survival from the date of endometrial cancer diagnosis to the date of death, as recorded in the Registered Persons Database. Survival was estimated using the KaplanMeier method and compared across groups using the log-rank test. Cox regression methods were used to assess factors associated with survival in the study population after verification of the proportional hazards assumption. Variables incorporated in the analyses included patient factors, such as age, comorbidity score, obesity, income and rurality, as well as marginalization indices; and disease factors, such as histology, stage, and previous history of cancer. Confidence intervals were constructed for statistics of interest. All tests and confidence intervals were two-sided and defined at the $\alpha=0.05$ level of significance. All analyses were performed using SAS version 9.2 (SAS Institute, Cary, NC) and R (www.r-project.org).

Funding

This study was supported by a grant (\#RD-196) from the Hamilton Health Sciences Juravinski Hospital and Cancer Center Foundation. The foundation awarding the grant uses a structured external peer reviewed process for scientific quality and prioritization in order to select projects meriting funding. The foundation otherwise plays no role in conducting the research funded or in presenting it.

\section{RESULTS}

A total of 20,228 women diagnosed with endometrial cancers between 2009-2017 were identified (Figure 1). Demographic, clinical and surgical data for patients stratified by a summary marginalization score are presented in Table 1. The highest quintile (Q5) represents patients living in the most marginalized neighborhoods.

Age distribution was slightly skewed, with more patients over seventy in the highest marginalization quintile. Highly marginalized patients were likely to be urban residents. Highly marginalized patients had more comorbidities as reflected by higher Charlson scores (20\% versus $27 \%$ had a score of 0 in the most and least marginalized quintiles, $\mathrm{p}<0.001$ ), but severe obesity (BMI $>40)$ was evenly distributed across quintiles.

Of patients with known cancer stage $(\mathrm{n}=14318), 74 \%(10,508)$ were diagnosed with stage I disease. $73 \%$ $(14,810 / 20,228)$ of endometrial cancers were of endometrioid histology. Patients in the most marginalized neighborhoods were more likely to present at more advanced stages: of patients with known stage, $70 \%$ $(1506 / 2138)$ of patients in quintile 5 presented with stage I disease, as compared to $76 \%(2281 / 3023)$ of patients in quintile $1(\mathrm{p}<0.001)$. Highly marginalized patients were also less likely to be treated surgically 
for their disease: $11 \%(332 / 3111)$ of patients in the highest marginalization quintile did not receive surgery, as compared to $7 \%(299 / 4107)$ of patients in the lowest quintile $(\mathrm{p}<0.001)$.

Figure 2 shows Kaplan-Meier survival curves of patients from diagnosis of endometrial cancer, by summary marginalization quintile. Marginalized patients had significantly worse overall survival (log-rank test, $\mathrm{p}<0.001$ ). 5-year survival was $77 \%$ (95\% CI, 75-79) among the most highly marginalized patients (quintile 5 ) as compared to $83 \%$ (95\% CI, 81-84) among the least marginalized patients (quintile 1), $\mathrm{p}<0.001$.

Regression analyses of patient- and disease-dependent factors associated with overall survival are shown in Table 2. On univariable analysis, income quintile, as well as two of three marginalization domains assessed (material deprivation and residential instability), were significantly associated with the risk of death ( $\mathrm{p}<0.001$ for all), as was the summary marginalization score. On multivariable analysis, after adjustment for year of diagnosis, age, Charlson score, obesity, prior cancer diagnosis, disease histology and stage, marginalization remained a significant independent predictor of survival, with a hazard ratio of 1.05 per quintile for death (95\% CI, 1.03-1.08, $\mathrm{p}<0.001)$. This translates into a hazard ratio of 1.22 when comparing the highest and lowest marginalization quintiles. Individual marginalization indices, including material deprivation (Q5 vs Q1: $\mathrm{HR}=1.32,95 \% \mathrm{CI}, 1.19-1.46$ ) and residential instability (Q5 vs Q1: $\mathrm{HR}=1.22,95 \% \mathrm{CI}, 1.10-1.35$ ) were also significantly associated with death after adjustment for year of diagnosis, age, Charlson score, obesity, prior cancer diagnosis, disease histology and stage (Table 3). The ethnic concentration index was not found to be prognostic for the risk of death either on univariable analysis or on multivariable analysis.

\section{DISCUSSION}

Main findings

Our analysis highlights a strong and independent association between social marginalization, as quantified by the Ontario Marginalization Index, and overall survival among endometrial cancer patients in Ontario's public healthcare system. Living in highly marginalized neighborhoods is associated with more limited survival in this patient population, even after adjusting for patient age, comorbidities, obesity, and disease factors such as histology and stage.

Interpretation

These findings reinforce information available from other contexts. Population studies from the US have consistently shown that socially and financially disadvantaged endometrial cancer patients have more limited prognosis. Two large studies using the National Cancer Database (NCDB) to evaluate endometrial cancer patients found that Black race, insurance status, lower income and education were all independently associated with increased mortality ${ }^{18,20}$. Similarly, a Surveillance, Epidemiology and End Results (SEER) cancer database study evaluating a large endometrial cancer cohort with long term follow up ${ }^{26}$ reported higher overall and cancer-specific mortality among Black patients, and tied this to disparities in presentation and treatment. However, publications from the US may not be transferrable to the Canadian context, due to the complexity of the American healthcare payer system and financially-driven barriers to access.

American data on the association between SDH and endometrial cancer outcomes focuses heavily on racial marginalization ${ }^{13,18,20,24,26,27}$. Race differs from ethnicity ${ }^{6}$ and is not routinely collected in Canadian administrative and healthcare databases. Our findings did not support an association between ethnic marginalization and overall survival in Ontarian women with endometrial cancer. The ethnic concentration domain of the Canadian Marginalization Index reflects the concentration of self-identified ethnic minorities and new immigrants in the community ${ }^{35}$. We postulate that the healthy immigrant effect may partially counterbalance the effects of social, cultural and financial marginalization often associated with ethnic concentration ${ }^{36}$. In support of this, a targeted analysis of immigration status in our patient population found that recent immigration to Canada is, in fact, associated with improved overall survival ( $\mathrm{HR}=0.58$ for new residents within 5 years, $\mathrm{p}=0.002$ ).

Data from other jurisdictions with public healthcare systems are also consistent with our findings in Ontario: Population-based studies from Sweden ${ }^{17}$ and from the UK ${ }^{16}$ have described higher rates of advanced-stage 
endometrial cancer among socially disadvantaged women; however, disease outcomes were not compared in these studies. Cooper et al report data from national statistics, including over 53,000 endometrial cancer patients, in England and South Wales ${ }^{37}$ between 1986-1999; they note a deprivation gap in endometrial cancer survival which has not narrowed over the 15-year study period. Finally, a comprehensive cancer registry study from Australia ${ }^{38}$ demonstrates a significant excess risk of death in disadvantaged endometrial cancer patients from communities with low levels of educational attainment and skilled employment.

Disparities in cancer incidence and outcomes in marginalized populations have been linked to adverse health behaviors ${ }^{39}$, and many publications on the association of SDH with cancer outcomes evaluate diseases with behavioral risk factors, such as lung cancer, head and neck tumors and cervical cancer rates ${ }^{7,40-42}$. We chose to focus on a neoplasm which is not associated with smoking or with sexual behavior in an attempt to mitigate confounders. However, obesity is a well-established risk factor for endometrial cancer ${ }^{43-46}$ and has consistently been linked to social marginalization ${ }^{47}$. We did not have access to individual-level BMI, but were able to capture severe obesity $(\mathrm{BMI}>40)$ through billing codes. We found that severe obesity was inversely associated with the risk of death; this may be explained by the fact that obesity increases the risk for estrogen-dependent tumors ${ }^{43-46}$, which are primarily well-differentiated and carry a better prognosis. This hypothesis is supported by the findings on multivariable analysis, where the association between obesity and improved survival did not persist when adjusted by disease histology and stage.

\section{Strengths and Limitations}

This is a robust population-based study, evaluating a large sample of patients and a broad spectrum of socio-demographic, clinical and pathological information through administrative databases that have been previously validated for healthcare research. The focus on endometrial cancer in a public healthcare system mitigates some common confounders in population studies on cancer care disparities. Finally, the use of validated Canadian measures of marginalization ${ }^{35}$ provides a unique opportunity to evaluate associations between inherently complex social, educational, financial and cultural barriers and cancer outcomes.

However, there are limitations to this study design which should be acknowledged. Many exposure variables, including marginalization indices, are based on neighborhood or community characteristics, which may create misclassification bias when assessing individual patients. Moreover, stage information and Charlson scores were missing in a large proportion of the women, though missing information was evenly distributed between marginalization quintiles. We were not able to conduct an analysis of recurrence rates and cancer-specific survival because recurrence are not captured in the Ontario cancer registry and because secondary causes of death are not reliably documented in death certificates. Although overall survival is considered an important and reproducible outcome in oncology, competing causes of death may confound the interpretation of this endpoint, especially in the endometrial cancer patient population ${ }^{48,49}$. Lastly, the association between marginalization and survival is confounded by other factors associated with SDH, including adverse health behaviors, stress, and chronic diseases and their sequelae, which we were not able to control for.

\section{Conclusion}

In this study, we demonstrate that social marginalization adversely impacts overall survival in endometrial cancer patients, independent of disease stage and other patient factors. Our study mitigates some of the confounders that commonly challenge health equity research in cancer care. Opportunities to reduce disparities in cancer outcomes exist across the entire disease trajectory, from prevention through early detection, access to care and healthcare utilization, treatment and survivorship. Further study is needed to identify targetable events in the cancer care pathway, and to assess the efficacy of healthcare systems interventions, in order to narrow the social chasm in cancer outcomes.

\section{Acknowledgements}

This study was funded with the generous support of the Hamilton Health Sciences Juravinski Hospital and Cancer Centre Foundation (RD-196). The funding source had no role in the planning, analysis or interpretation of the study data. 
Access to administrative data was facilitated by the Institute for Clinical and Evaluative Sciences, through the Data \& Analytics Services funded by the Canadian Institutes of Health Research, the Ontario Ministry of Health and Long-Term Care and the Ontario Ministry of Research and Innovation.

\section{Author Contribution}

Limor Helpman conceptualized the project and planned the analyses, interpreted the data and wrote the manuscript. Greg Pond assisted with planning, performed the analyses and edited the manuscript. Laurie Elit, Kara Schnarr, Iwa Kong and Laura Anderson assisted with data interpretation and edited the manuscript. Hsien Seow contributed to analysis planning and data interpretation, and edited the manuscript.

\section{Disclosure - Conflict of Interests}

Dr. Helpman, Dr. Elit, Dr. Anderson, Dr. Kong, Dr. Schnarr and Dr. Seow have no conflict of interest to disclose. Dr. Pond reports personal fees from Astra-Zeneca and personal fees from Takeda, outside the scope of the submitted work; a close family member of Dr. Pond is an employee of Roche Canada Ltd, and owns stock in Roche.

\section{Funding}

This study was supported by a grant (\#RD-196) from the Hamilton Health Sciences Juravinski Hospital and Cancer Center Foundation.

\section{Details of Ethical Approval}

The study, using de-identified secondary data analysis, was reviewed and exempted by the Hamilton Health Sciences integrated research ethics board (\#7732-C).

\section{REFERENCES}

1. Singh G, Daus G, Allender M, et al. Social Determinants of Health in the United States: Addressing Major Health Inequality Trends for the Nation, 1935-2016. Int J MCH AIDS . 2017;6(2):139-164. doi:10.21106/ijma.236

2. Smedley BD, Stith AY, Nelson AR. Unequal Treatment: Confronting Racial and Ethnic Disparities in Health Care (with CD) .; 2003. doi:10.17226/12875

3. Marmot M, Friel S, Bell R, Houweling TA, Taylor S. Closing the gap in a generation: health equity through action on the social determinants of health. Lancet . 2008;372(9650):1661-1669. doi:10.1016/S01406736(08)61690-6

4. Alcaraz KI, Wiedt TL, Daniels EC, Yabroff KR, Guerra CE, Wender RC. Understanding and addressing social determinants to advance cancer health equity in the United States: A blueprint for practice, research, and policy. CA Cancer J Clin . 2020;70(1):31-46. doi:10.3322/caac.21586

5. Sayani A. Health equity in national cancer control plans: An analysis of the ontario cancer plan. Int $J$ Heal Policy Manag . 2019;8(9):550-556. doi:10.15171/ijhpm.2019.40

6. Temkin SM, Rimel BJ, Bruegl AS, Gunderson CC, Beavis AL, Doll KM. A contemporary framework of health equity applied to gynecologic cancer care: A Society of Gynecologic Oncology evidenced-based review.Gynecol Oncol . 2018;149(1):70-77. doi:10.1016/j.ygyno.2017.11.013

7. Ward E, Jemal A, Cokkinides V, et al. Cancer Disparities by Race/Ethnicity and Socioeconomic Status. CA Cancer J Clin . 2004;54(2):78-93. doi:10.3322/canjclin.54.2.78

8. Booth CM, Li G, Zhang-Salomons J, Mackillop WJ. The impact of socioeconomic status on stage of cancer at diagnosis and survival: A population-based study in Ontario, Canada. Cancer . 2010;116(17):4160-4167. doi: $10.1002 /$ cncr. 25427

9. WHO. WHO Report on Cancer: Setting Priorities Investing Wisely and Providing Care for All. ; 2020. 
10. McDaniel JT, Nuhu K, Ruiz J, Alorbi G. Social determinants of cancer incidence and mortality around the world: an ecological study. Glob Health Promot . 2019;26(1):41-49. doi:10.1177/1757975916686913

11. Yap ML, Oar A, Moraes FY, Ilbawi A. An Evidence-Based National Cancer Control Program (NCCP) Quality Assessment Checklist. J Glob Oncol . 2018. doi:10.1200/jgo.18.66800

12. Felix AS, Brinton LA. Cancer progress and priorities: Uterine cancer. Cancer Epidemiol Biomarkers Prev . 2018;27(9):985-994. doi:10.1158/1055-9965.EPI-18-0264

13. Madison T, Schottenfeld D, James SA, Schwartz AG, Gruber SB. Endometrial cancer: Socioeconomic status and racial/ethnic differences in stage at diagnosis, treatment, and survival. Am J Public Health . 2004;94(12):2104-2111. doi:10.2105/AJPH.94.12.2104

14. Robinson KM, Christensen KB, Ottesen B, Krasnik A. Socio-demographic factors, comorbidity and diagnostic delay among women diagnosed with cervical, endometrial or ovarian cancer. Eur $J$ Cancer Care (Engl) . 2011;20(5):653-661. doi:10.1111/j.1365-2354.2011.01259.x

15. Doll KM, Winn AN, Goff BA. Untangling the Black-White mortality gap in endometrial cancer: a cohort simulation. Am J Obstet Gynecol . 2017;216(3):324-325. doi:10.1016/j.ajog.2016.12.023

16. Lyratzopoulos G, Abel GA, Brown CH, et al. Socio-demographic inequalities in stage of cancer diagnosis: Evidence from patients with female breast,lung, colon, rectal, prostate, renal, bladder, melanoma, ovarian and endometrial cancer. Ann Oncol . 2013;24(3):843-850. doi:10.1093/annonc/mds526

17. Svanvik T, Marcickiewicz J, Sundfeldt K, Holmberg E, Strömberg U. Sociodemographic disparities in stage-specific incidences of endometrial cancer: a registry-based study in West Sweden, 1995-2016. Acta Oncol (Madr) . 2019;58(6):845-851. doi:10.1080/0284186X.2019.1581947

18. Strohl AE, Feinglass JM, Shahabi S, Simon MA. Surgical wait time: A new health indicator in women with endometrial cancer. Gynecol Oncol . 2016;141(3):511-515. doi:10.1016/j.ygyno.2016.04.014

19. Fader AN, Matsuno Weise R, Sinno AK, et al. Utilization of minimally invasive surgery in endometrial cancer care: A Quality and cost disparity. In: Obstetrics and Gynecology . Vol 127. ; 2016:91-100. doi:10.1097/AOG.0000000000001180

20. Fader AN, Habermann EB, Hanson KT, Lin JF, Grendys EC, Dowdy SC. Disparities in treatment and survival for women with endometrial cancer: A contemporary national cancer database registry analysis. Gynecol Oncol . 2016;143(1):98-104. doi:10.1016/j.ygyno.2016.07.107

21. Bregar AJ, Alejandro Rauh-Hain J, Spencer R, et al. Disparities in receipt of care for highgrade endometrial cancer: A National Cancer Data Base analysis. Gynecol Oncol . 2017;145(1):114-121. doi:10.1016/j.ygyno.2017.01.024

22. Foote JR, Gaillard S, Broadwater G, et al. Disparities in the surgical staging of high-grade endometrial cancer in the United States. Gynecol Oncol Res Pract . 2017;4(1):1-8. doi:10.1186/s40661-016-0036-3

23. Osborn V, Schwartz D, Lee YC, et al. Patterns of care of IMRT usage in postoperative management of uterine cancer. Gynecol Oncol . 2017;144(1):130-135. doi:10.1016/j.ygyno.2016.11.017

24. Yap OWS, Matthews RP. Racial and ethnic disparities in cancers of the uterine corpus. J Natl Med Assoc . 2006;98(12):1930-1933.

25. Randall TC, Armstrong K. Differences in treatment and outcome between African-American and white women with endometrial cancer.J Clin Oncol . 2003;21(22):4200-4206. doi:10.1200/JCO.2003.01.218

26. Sud S, Holmes J, Eblan M, Chen R, Jones E. Clinical characteristics associated with racial disparities in endometrial cancer outcomes: A surveillance, epidemiology and end results analysis. Gynecol Oncol . 2018;148(2):349-356. doi:10.1016/j.ygyno.2017.12.021 
27. Dolly D, Mihai A, Rimel BJ, et al. A delay from diagnosis to treatment is associated with a decreased overall survival for patients with endometrial cancer. Front Oncol . 2016;6(FEB):1-5. doi:10.3389/fonc.2016.00031

28. OECD Interactive Tool: International Comparisons - Peer Countries, Ontario .; 2019. https://www.cihi.ca/en/oecd-interactive-tool-peer-countries-on.

29. Kumachev A, Trudeau ME, Chan KKW. Associations among socioeconomic status, patterns of care and outcomes in breast cancer patients in a universal health care system: Ontario's experience. Cancer . 2016;122(6):893-898. doi:10.1002/cncr.29838

30. Kagedan DJ, Abraham L, Goyert N, et al. Beyond the dollar: Influence of sociodemographic marginalization on surgical resection, adjuvant therapy, and survival in patients with pancreatic cancer. Cancer . 2016;122(20):3175-3182. doi:10.1002/cncr.30148

31. Anderson LN, Cotterchio M, Boucher BA, Kreiger N. Phytoestrogen intake from foods, during adolescence and adulthood, and risk of breast cancer by estrogen and progesterone receptor tumor subgroup among Ontario women. Int J Cancer . 2013;132(7):1683-1692. doi:10.1002/ijc.27788

32. Allemani C, Weir HK, Carreira H, et al. Global surveillance of cancer survival 1995-2009: Analysis of individual data for 25676887 patients from 279 population-based registries in 67 countries (CONCORD-2). Lancet . 2015;385(9972):977-1010. doi:10.1016/S0140-6736(14)62038-9

33. Deyo RA, Cherkin DC, Ciol MA. Adapting a clinical comorbidity index for use with ICD-9-CM administrative databases. J Clin Epidemiol . 1992;45(6):613-619. doi:10.1016/0895-4356(92)90133-8

34. Soobader MJ, LeClere FB, Hadden W, Maury B. Using aggregate geographic data to proxy individual socioeconomic status: Does size matter? Am J Public Health . 2001;91(4):632-636. doi:10.2105/AJPH.91.4.632

35. Matheson FI, Dunn JR, Smith KLW, Moineddin R, Glazier RH. Development of the Canadian Marginalization index: A new tool for the study of inequality. Can J Public Heal . 2012;103(SUPPL.2):3-5. doi:10.17269/cjph.103.3096

36. McDonald JT, Farnworth M, Liu Z. Cancer and the healthy immigrant effect: a statistical analysis of cancer diagnosis using a linked Census-cancer registry administrative database. BMC Public Health . 2017;17(1):1-14. doi:10.1186/s12889-017-4190-2

37. Cooper N, Quinn MJ, Rachet B, Mitry E, Coleman MP. Survival from cancer of the uterus in england and wales up to 2001. Br J Cancer . 2008;99:S65-S67. doi:10.1038/sj.bjc.6604591

38. Stanbury JF, Baade PD, Yu Y, Yu XQ. Cancer survival in New South Wales, Australia: Socioeconomic disparities remain despite overall improvements. BMC Cancer . 2016;16(1):48. doi:10.1186/s12885-016-2065-Z

39. Hughes MC, Baker TA, Kim H, Valdes EG. Health behaviors and related disparities of insured adults with a health care provider in the United States, 2015-2016. Prev Med (Baltim) . 2019;120(December 2018):42-49. doi:10.1016/j.ypmed.2019.01.004

40. Danos D, Leonardi C, Gilliland A, et al. Increased risk of hepatocellular carcinoma associated with neighborhood concentrated disadvantage. Front Oncol . 2018;8(SEP):1-9. doi:10.3389/fonc.2018.00375

41. Jensen KE, Hannibal CG, Nielsen A, et al. Social inequality and incidence of and survival from cancer of the female genital organs in a population-based study in Denmark, 1994-2003. Eur J Cancer . 2008;44(14):2003-2017. doi:10.1016/j.ejca.2008.06.014

42. Wen X, Wen D, Yang Y, Chen Y, Wang G, Shan B. Urban-Rural Disparity in Helicobacter Pylori Infection-Related Upper Gastrointestinal Cancer in China and the Decreasing Trend in Parallel with Socioeconomic Development and Urbanization in an Endemic Area. Ann Glob Heal . 2017;83(3-4):444-462. doi:10.1016/j.aogh.2017.09.004 
43. Raglan O, Kalliala I, Markozannes G, et al. Risk factors for endometrial cancer: An umbrella review of the literature. Int J Cancer . 2019;145(7):1719-1730. doi:10.1002/ijc.31961

44. Allen NE, Key TJ, Dossus L, et al. Endogenous sex hormones and endometrial cancer risk in women in the European Prospective Investigation into Cancer and Nutrition (EPIC). Endocr Relat Cancer . 2008;15(2):485-497. doi:10.1677/ERC-07-0064

45. Feinberg J, Albright B, Black J, et al. Ten-year comparison study of type 1 and 2 endometrial cancers: Risk factors and outcomes. Gynecol Obstet Invest . 2019;84(3):290-297. doi:10.1159/000493132

46. Busch EL, Crous-Bou M, Prescott J, et al. Endometrial cancer risk factors, hormone receptors, and mortality prediction. Cancer Epidemiol Biomarkers Prev . 2017;26(5):727-735. doi:10.1158/1055-9965.EPI16-0821

47. Newton S, Braithwaite D, Akinyemiju TF. Socio-economic status over the life course and obesity: Systematic review and meta-analysis. Xiao G, ed. PLoS One . 2017;12(5):e0177151. doi:10.1371/journal.pone.0177151

48. Ward KK, Shah NR, Saenz CC, McHale MT, Alvarez EA, Plaxe SC. Cardiovascular disease is the leading cause of death among endometrial cancer patients. Gynecol Oncol . 2012;126(2):176-179. doi:10.1016/j.ygyno.2012.04.013

49. Nicholas Z, Hu N, Ying J, Soisson P, Dodson M, Gaffney DK. Impact of comorbid conditions on survival in endometrial cancer. Am J Clin Oncol . 2014;37(2):131-134. doi:10.1097/COC.0b013e318277d5f4

Table 1: Characteristics of study population, stratified by summary marginalization quintile.

\begin{tabular}{|c|c|c|c|c|c|}
\hline & & $\begin{array}{l}\text { Marginalization } \\
\text { Quintile }^{\mathbf{a}}\end{array}$ & $\begin{array}{l}\text { Marginalization } \\
\text { Quintile }^{\mathrm{a}}\end{array}$ & $\begin{array}{l}\text { Marginalization } \\
\text { Quintile }^{\mathrm{a}}\end{array}$ & \\
\hline & & Q1 & Q3 & Q5 & p-value \\
\hline & $\mathrm{N}(\%)$ & 4107 & 4731 & 3111 & \\
\hline \multirow[t]{3}{*}{ Age } & $18-3940-49$ & 48 (1.2) 255 & $105(2.2) 371$ & $82(2.6) 257$ & $<0.001$ \\
\hline & 50-59 60-69 & (6.2) $1176(28.7)$ & (7.8) $1261(26.7)$ & $(8.2) 835(26.8)$ & \\
\hline & $70-7980+$ & $\begin{array}{l}1507(36.7) 831 \\
(20.2) 290(7.1)\end{array}$ & $\begin{array}{l}1624(34.3) 919 \\
(19.4) 451(9.5)\end{array}$ & $\begin{array}{l}1065(34.2) 556 \\
(18.9) 316(10.2)\end{array}$ & \\
\hline \multirow{3}{*}{$\begin{array}{l}\text { Charlson } \\
\text { Score }\end{array}$} & $01-23+\mathrm{No}$ & $1102(26.8) 886$ & $1093(23.1) 1112$ & $629(20.2) 740$ & $<0.001$ \\
\hline & Admission $^{\mathrm{b}}$ & (21.6) $176(4.3)$ & $(23.5) 279(5.9)$ & (23.8) $204(6.6)$ & \\
\hline & & $1943(47.3)$ & $2247(47.5)$ & $1538(49.4)$ & \\
\hline \multicolumn{6}{|l|}{ Obesity } \\
\hline \multirow{2}{*}{$\begin{array}{l}\text { Income } \\
\text { Quintile }\end{array}$} & 12345 & $30(0.7) 210$ & 539 (11.4) 1287 & 1986 (64.0) 771 & $<0.001$ \\
\hline & & $\begin{array}{l}(5.1) 587(14.3) \\
1172(28.5) 2107 \\
(51.3)\end{array}$ & $\begin{array}{l}(27.2) 1452 \\
(30.7) 959(20.3) \\
493(10.4)\end{array}$ & $\begin{array}{l}(24.9) 207(6.7) \\
86(2.8) 53(1.7)\end{array}$ & \\
\hline \multirow{2}{*}{\multicolumn{2}{|c|}{ Rural }} & $877(21.4)$ & $507(10.7)$ & NR & $<0.001$ \\
\hline & & & & & \\
\hline \multirow{6}{*}{$\begin{array}{l}\text { Residence } \\
\text { Histology }\end{array}$} & Endometrioid & 3095 (75.4) 153 & 3409 (72.1) 194 & 2199 (70.7) 305 & $<0.001$ \\
\hline & Serous Mixed & (3.7) $60(1.5) 248$ & (4.1) 67 (1.4) 355 & (9.8) $241(7.8)$ & \\
\hline & Carcinosarcoma & (6.0) $164(4.0) 54$ & $(7.5) 180(3.8) 60$ & $147(4.7) 43(1.4)$ & \\
\hline & Clear Cell & (1.3) $333(8.1)$ & $(1.3) 466(9.9)$ & $58(1.9) 118(3.8)$ & \\
\hline & Undifferentiated & & & & \\
\hline & & & & & \\
\hline
\end{tabular}




\begin{tabular}{|c|c|c|c|c|c|}
\hline & & $\begin{array}{l}\text { Marginalization } \\
\text { Quintile }^{\mathrm{a}}\end{array}$ & $\begin{array}{l}\text { Marginalization } \\
\text { Quintile }^{\mathrm{a}}\end{array}$ & $\begin{array}{l}\text { Marginalization } \\
\text { Quintile }^{\mathrm{a}}\end{array}$ & \\
\hline Stage & 1234 Unknown & $\begin{array}{l}2281(55.5) 264 \\
(6.4) 298(7.3) \\
180(4.4) 1084 \\
(26.4)\end{array}$ & $\begin{array}{l}2419(51.1) 325 \\
(6.9) 364(7.7) \\
174(3.7) 1449 \\
(30.6)\end{array}$ & $\begin{array}{l}1506(48.4) 195 \\
(6.3) 289(9.3) \\
148(4.8) 973 \\
(31.3)\end{array}$ & $<0.001$ \\
\hline $\begin{array}{l}\text { Prior } \\
\text { Cancer }^{\mathrm{c}}\end{array}$ & & $224(5.5)$ & $219(4.6)$ & $151(4.9)$ & 0.42 \\
\hline $\begin{array}{l}\text { No Surgery } \\
\text { Performed }\end{array}$ & & $299(7.3)$ & $435(9.2)$ & $332(10.7)$ & $<0.001$ \\
\hline $\begin{array}{l}\text { Surgery } \\
>180 d \text { after } \\
\text { diagnosis } \\
\text { MIS }^{d}\end{array}$ & & $81(2.0)$ & $113(2.4)$ & $84(2.7)$ & 0.006 \\
\hline $\begin{array}{l}\text { Surgeon } \\
\text { Specialty }\end{array}$ & $\begin{array}{l}\text { Gynecologic } \\
\text { Oncologist } \\
\text { General } \\
\text { Gynecologist } \\
\text { Other/Unknown }\end{array}$ & $\begin{array}{l}1574(41.3) 1971 \\
(51.8) 273(6.9)\end{array}$ & $\begin{array}{l}1711(39.8) 2258 \\
(52.6) 327(7.7)\end{array}$ & $\begin{array}{l}1196(43.0) 1370 \\
(49.3) 213(7.6)\end{array}$ & $<0.001$ \\
\hline $\begin{array}{l}\text { Hospital Type } \\
\text { for Surgery }\end{array}$ & $\begin{array}{l}\text { Community } \\
\text { Teaching } \\
\text { Other/Unknown }\end{array}$ & $\begin{array}{l}1912(50.2) 1556 \\
(40.9) 340(9.0)\end{array}$ & $\begin{array}{l}2322(54.1) 1562 \\
(36.4) 412(9.6)\end{array}$ & $\begin{array}{l}1261(45.4) 1204 \\
(43.3) 314(11.3)\end{array}$ & $<0.001$ \\
\hline
\end{tabular}

${ }^{\text {a }}$ 1- lowest marginalization quintile, least marginalized; Q5- highest marginalization quintile, most marginalized.

Summary score including material deprivation, ethnic concentration and residential instability domains is used.

${ }^{\mathrm{b}}$ no admission in the year preceding surgery precludes a calculation of the Charlson-Deyo comorbidity score

${ }^{\mathrm{c}}$ Prior cancer within 5 years of diagnosis

d MIS - Minimally Invasive Surgery

Table 2: Cox regression analysis of factors associated with overall survival.

Univariable and multivariable regression analyses of patient- and disease-dependent predictors of survival including marginalization indices.

\begin{tabular}{llllll}
\hline Factor & Comparison & Univariable & Univariable & Multivariable & Multivariable \\
\hline & & Hazards Ratio & p-value & Hazards Ratio & p-value \\
& & $(95 \% \mathrm{CI})$ & & $(95 \% \mathrm{CI})$ & \\
Year of & / year & $0.97(0.96$, & $<0.001$ & $0.96(0.94$, & $<0.001$ \\
Diagnosis & & $0.99)$ & & $0.97)$ & \\
Age Group & / age group & $1.41(1.38$, & $<0.001$ & $1.34(1.31$, & $<0.001$ \\
& & $1.43)$ & & $1.36)$ & \\
Charlson & $01-23-45+$ No & $0.90(0.83,0.98)$ & $<0.001$ & $0.87(0.80,0.95)$ & $<0.001$ \\
Score & Admission & & & $0.96(0.88,1.04)$ & \\
& & $1.00(0.92,1.08)$ & & $1.34(1.17,1.53)$ & \\
& & $1.61(1.41,1.83)$ & & $2.16(1.81,2.58)$ & \\
& & $4.78(4.02,5.68)$ & & Reference &
\end{tabular}




\begin{tabular}{|c|c|c|c|c|c|}
\hline Factor & Comparison & Univariable & Univariable & Multivariable & Multivariable \\
\hline $\begin{array}{l}\text { Severe } \\
\text { Obesity } \\
(\text { BMI>40) }\end{array}$ & Yes vs No & $\begin{array}{l}0.54(0.48 \\
0.59)\end{array}$ & $<0.001$ & $\begin{array}{l}0.93(0.84, \\
1.03)\end{array}$ & 0.17 \\
\hline Histology & $\begin{array}{l}\text { Endometrioid } \\
\text { Serous Mixed } \\
\text { Carcinosarcoma } \\
\text { Clear Cell } \\
\text { Undifferentiated } \\
\text { Other/Missing }\end{array}$ & $\begin{array}{l}\text { Reference } 5.26 \\
(4.82,5.74) 2.30 \\
(2.05,2.58) 7.33 \\
(6.60,8.15) 4.23 \\
(3.48,5.15) 13.45 \\
(11.62,15.57) \\
4.91(4.36,5.52)\end{array}$ & $<0.001$ & $\begin{array}{l}\text { Reference } 3.59 \\
(3.22,4.01) 2.06 \\
(1.69,2.51) 1.77 \\
(1.58,1.99) 3.07 \\
(2.72,3.46) 2.41 \\
(2.20,2.65) 7.11 \\
(6.11,8.26)\end{array}$ & $<0.001$ \\
\hline Best Stage & 1234 Unknown & $\begin{array}{l}\text { Reference } 2.33 \\
(2.05,2.65) 5.33 \\
(4.84,5.87) 20.45 \\
(18.53,22.57) \\
2.52(2.32,2.74)\end{array}$ & $<0.001$ & $\begin{array}{l}\text { Reference } 1.88 \\
(1.65,2.14) 3.54 \\
(3.21,3.92) 10.23 \\
(9.19,11.39) \\
2.28(2.09,2.49)\end{array}$ & $<0.001$ \\
\hline Prior Cancer & Yes vs No & $\begin{array}{l}1.94(1.73 \\
2.18)\end{array}$ & $<0.001$ & $\begin{array}{l}1.30(1.15 \\
1.47)\end{array}$ & $<0.001$ \\
\hline $\begin{array}{l}\text { Income } \\
\text { Quintile }\end{array}$ & / quintile & $\begin{array}{l}0.93(0.91 \\
0.96)\end{array}$ & $<0.001$ & c & \\
\hline $\begin{array}{l}\text { Rural } \\
\text { Residence }\end{array}$ & Yes vs No & $\begin{array}{l}0.98(0.89 \\
1.08)\end{array}$ & 0.67 & c & \\
\hline $\begin{array}{l}\text { Material } \\
\text { Deprivation } \\
\text { Quintile }\end{array}$ & / quintile & $\begin{array}{l}1.08(1.05, \\
1.10)\end{array}$ & $<0.001$ & c & \\
\hline $\begin{array}{l}\text { Ethnic Con- } \\
\text { centration } \\
\text { Quintile }\end{array}$ & / quintile & $\begin{array}{l}1.01(0.99 \\
1.03)\end{array}$ & 0.41 & c & \\
\hline $\begin{array}{l}\text { Residential } \\
\text { Instability } \\
\text { Quintile }\end{array}$ & / quintile & $\begin{array}{l}1.11(1.08 \\
1.13)\end{array}$ & $<0.001$ & c & \\
\hline $\begin{array}{l}\text { Summary } \\
\text { Marginaliza- } \\
\text { tion } \\
\text { Quintileb }^{b}\end{array}$ & / quintile & $\begin{array}{l}1.09(1.07, \\
1.12)\end{array}$ & $<0.001$ & $\begin{array}{l}1.05(1.03, \\
1.08)\end{array}$ & $<0.001$ \\
\hline
\end{tabular}

${ }^{a}$ no admission in the year preceding surgery precludes a calculation of the Charlson-Deyo comorbidity score

${ }^{\mathrm{b}}$ Summary score includes material deprivation, ethnic concentration and residential instability domains

${ }^{\mathrm{c}}$ Individual marginalization indices, income quintiles and rurality were not included in the multivariable model due to significant collinearity between them.

Table 3: Cox regression analysis of the association of overall survival with individual marginalization domains.

Multivariable regression analyses for each marginalization domain, adjusted for other patient- and diseasedependent factors as listed ${ }^{\mathrm{a}}$. 


\begin{tabular}{llll}
\hline $\begin{array}{l}\text { Marginalization } \\
\text { Domain }\end{array}$ & quintile & Hazards Ratio $(95 \%$ & p-value \\
\hline Residential Instability & 12345 & Reference $1.12(1.00$, & $<0.001$ \\
& & $1.25) 1.04(0.93,1.17)$ & \\
& & $1.19(1.06,1.32) 1.32$ & \\
& & $(1.19,1.46)$ & \\
Material Deprivation & 12345 & Reference $1.06(0.95$, & $<0.001$ \\
& & $1.17) 1.07(0.96,1.19)$ & \\
& & $1.09(0.98,1.21) 1.22$ & \\
Ethnic Concentration & 12345 & $(1.10,1.35)$ & \\
& & Reference $0.97(0.88$, & 0.74 \\
& & $1.07) 0.98(0.88,1.08)$ & \\
& & $0.96(0.87,1.07) 1.02$ & \\
& & $(0.92,1.12)$ & \\
\hline
\end{tabular}

${ }^{a}$ Model adjusted for year of diagnosis, age, Charlson score, obesity, prior cancer diagnosis, stage and histology.

\section{FIGURE CAPTIONS}

Figure 1. STROBE flow diagram of cases included in the analysis.

Figure 2. Overall survival by marginalization quintile.

Kaplan-Meier survival curves of patients, stratified by marginalization quintile. Log rank test, $\mathrm{p}<0.0001$.

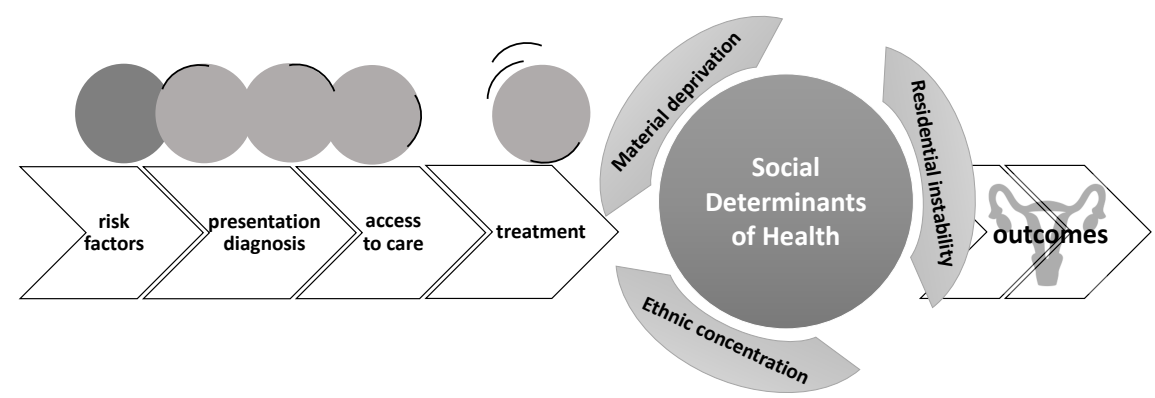




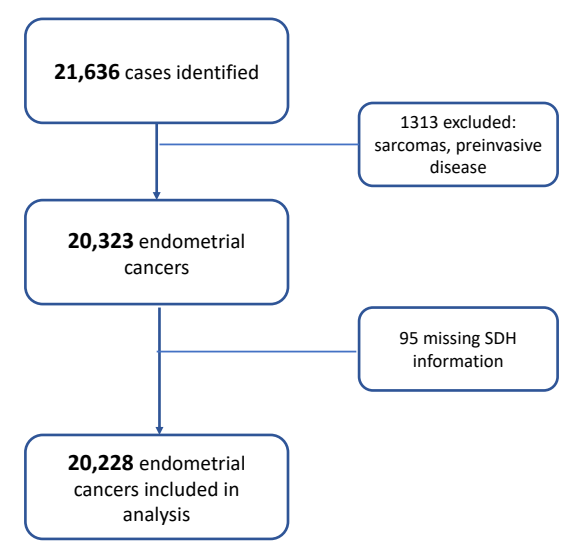




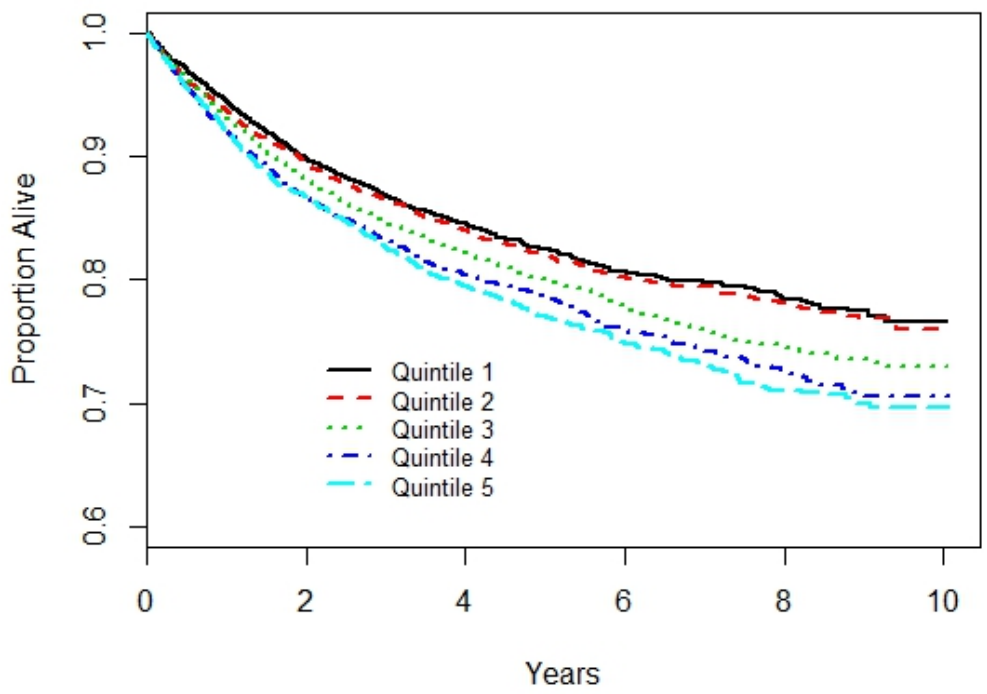

